\section{Cureus}

\title{
Castleman Disease: A Rare Condition with Endocrine Manifestations
}

\author{
Carmen E. Cervantes ${ }^{1}$, Ricardo Correa ${ }^{2}$ \\ 1. Internal Medicine, Aventura Hospital and Medical Center 2. NICHD, National Institute of Health
}

$\square$ Corresponding author: Carmen E. Cervantes, karmenelena11@gmail.com

Disclosures can be found in Additional Information at the end of the article

\section{Abstract}

Castleman disease (CD) most commonly affects lymphoid tissues in the thorax, abdomen, pelvis, and neck. Extralymphatic tissues, such as lacrimal glands, lung, pancreas, larynx, parotid, meninges, and even muscles, have also been reported as sites. The etiology is unknown and its incidence has not been reported in the literature. Castleman disease can be classified clinically into a unicentric or multicentric form, depending on the number of lymph nodes involved, and histologically into a hyaline vascular variant, plasma cell, mixed cellular, or plasmablastic variant. The disease has a predominantly inflammatory background, reflected in high levels of vascular endothelial growth factor (VEGF) and interleukin-6 (IL-6). The role of cytokines in CD explains the clinical presentation. The clinical scenario varies widely, based mainly on the histologic type. Unicentric CD usually presents without symptomatology, whereas multicentric manifests with fatigue, abdominal or thoracic pain, cytopenias, and/or Bsymptoms (10\% weight loss in the last six months, nocturnal diaphoresis, and fever). The endocrinopathy has a wide range of manifestations, affecting either the pituitary or other target organs. Achieving the diagnosis is complicated and there is no laboratory or imaging pathognomonic for this disease. The gold standard is an excisional biopsy from an affected lymph node. The treatment depends on the type of CD. Unicentric CD has a good response to excisional surgery. However, in multicentric CD (MCD), surgery may provide transient relief of symptoms but with a rebound effect, so it is not considered a good method. The use of chemotherapy, monoclonal antibodies, glucocorticoids, and thalidomide has shown some improvement in MCD.

Categories: Internal Medicine, Miscellaneous, Oncology

Keywords: castleman disease, angiofollicular lymph node hyperplasia, poems syndrome, osteosclerotic myeloma

\section{Introduction And Background}

Received 10/08/2015

Review began 10/23/2015

Review ended 11/10/2015

Published 11/17/2015

\section{(c) Copyright 2015}

Cervantes et al. This is an open access article distributed under the terms of the Creative Commons Attribution License CC-BY 3.0., which permits unrestricted use, distribution, and reproduction in any medium, provided the original author and source are credited.
In 1956, Castleman disease (CD), also known as angiofollicular lymph node and giant lymph node hyperplasia, was first described in 13 subjects with mediastinal lymphadenopathy [1-4]. The most common affected sites include lymphoid tissues in the thorax in $70 \%$ of cases, abdomen and pelvis in 15\%, and the neck in 15\% [4-6]. Extralymphatic involvement may include lacrimal glands, lung, pancreas, larynx, parotid, meninges, and even muscles of the extremities [4, 6-12].

The etiology is unknown, although it has been associated with human herpesvirus-8 (HHV-8) infection, particularly, but not only, in HIV-positive patients [2]. CD has a clinical and histological classification described in Table $1[2,4]$. 


\section{Cureus}

Clinical (Depending on the Number of Lymph Nodes Involved)

Unicentric (UCD) (47\%-81\%)

Multicentric (MCD)

\section{Histological}

Hyaline vascular

Plasma cell

Mixed cellular

Plasmablastic variant (also known as HHV-8 associated MCD)

\section{TABLE 1: Castleman Disease Classification}

Systemic symptoms are mostly related to the presence of plasma cells, although some hyaline vascular form cases have displayed them as well [2]. Other clinical entities may accompany CD, such as lymphoid neoplasms, POEMS syndrome (coined to refer to polyneuropathy, organomegaly, endocrinopathy, $\mathrm{M}$ protein, and skin changes), amyloidosis, and osteosclerotic myeloma. The diversity of its presentation stands as a challenge for its diagnosis $[2,11]$.

\section{Review}

\section{Epidemiology}

Due to the rarity of the disease, there is no incidence reported in the literature. However, a recent study attempted to calculate it, obtaining an incidence of 21 and 25 per million personyears, which confirms its orphan disease status. Likewise, they estimated that $23 \%$ of the patients had multicentric Castleman disease (MCD) [13]. The syndrome appears to be more common among Asian people, especially Japanese [3, 8, 13].

The hyaline vascular type usually presents as unicentric Castleman disease (UCD) in 76\% to 91\% of cases, involving a single node or a localized group of nodes. It affects both genders equally. The median age reported lies in the fourth decade $[2,13]$. The plasma cell variant is regularly multicentric, although it occurs in $9 \%$ to $24 \%$ of localized UCD (and shares its epidemiologic characteristics). Most plasma cell variants in MCD affects subjects in the sixth decade [2].

In HIV-positive individuals, MCD tends to occur in the fourth decade of life, prevailing in men $[2,13]$.

\section{Physiopathology}

The disease has a predominant inflammatory background, reflected in high levels of vascular endothelial growth factor (VEGF), c-Myc-dependent transcription factor and IL-6. This cytokine acts both as a differentiation factor for macrophages as well as a hepatocyte and B cell stimulating factor. It also has a role in the modulation of immune and central nervous systems and bone metabolism [14-15]. Likewise, a viral IL-6 (analog to its human form) encoded by HHV-8 activates the Janus kinase/signal transducer and activator of transcription (JAK-STAT) signaling pathway, which stimulates more cell types and potentiates the effect of human IL-6. This is translated into an increased angiogenesis and proliferation of polyclonal IgM-lambda plasma cells in the follicles of affected nodes [2, 4, 14]. Autoantibodies produced by plasma cells have been suggested as the effectors of the endocrinopathy; nonetheless, no circulating 
forms against the hormones or its receptors have been found [14, 16]. Apparently, VEGF affects the endocrine axes by inducing an imbalance in angiogenic factors that regulate hormonal secretion [15].

IL-6 causes a systemic response by stimulating hepatocytes to produce C-reactive protein [4, 14]. It also increases the levels of the hormone hepcidin, which plays a leading role in anemia of chronic diseases [17-18].

Bone remodeling depends on cytokine stimulation of resorption and apposition, featuring RANKL (receptor activator of nuclear factor kappa-B ligand) as the predominant effector. However, IL-6 also exhibits an important function, whose relevance rises in this disease as its blood levels reach upper limits. IL-6 receptors are expressed in low levels in osteoblasts, enhancing their differentiation into osteocytes and inhibiting apoptosis. Moreover, in an indirect way, IL-6 displays an inhibitory effect on osteoclasts, thus, decreasing bone resorption [14].

The roles of both cytokines (IL-6 and VEGF) in CD have explained interchangeably the clinic presentation of these patients. An elevated VEGF level has been considered one of the criteria for POEMS syndrome, and due to the higher prevalence of bone lesions in this group, its levels have been associated with the degree of bone compromise $[14,16]$.

Multicentric and HHV-8 positive variants are risk factors for the development of complications, such as Hodgkin and non-Hodgkin lymphomas, as well as Kaposi sarcoma [2, 13].

\section{Clinical manifestations}

The clinical scenario varies widely, based mainly in its histologic type. UCD (usually the hyaline vascular variant) can be asymptomatic or present a course with manifestations secondary to compression. However, detailed cases have a course with systemic signs [19-20]. On the other hand, MCD has shown a greater clinical spectrum in connection with the presence of plasma cells, which ranges from fatigue and B-symptoms to pleural effusions and organomegaly that may mimic systemic infections or even hematologic neoplasms [4].

Cronin, et al. established two subgroups of MCD, though not well defined because they were not distinguished in older reports: MCD associated with HHV-8 and MCD not otherwise specified [2]. The difference between both groups is relevant since MCD associated with HHV-8 is usually present in HIV patients; apparently, only a single case has been reported of MCD involving an HIV-positive patient with a negative HHV-8 viral panel [2, 20]. This subgroup has a different course and a poorer prognosis, as it tends to progress to a large B-cell lymphoma (HHV-8-positive plasmablastic lymphoma) [2].

Systemic manifestations, such as fatigue, abdominal or thoracic pain, cytopenias, and Bsymptoms, are most common in MCD [4, 21-22].

POEMS syndrome accounts for polyneuropathy, organomegaly, endocrinopathy, M protein or gammopathy, and skin changes. Its diagnosis is made with two major criteria and one minor criterion. The major criteria comprise polyneuropathy, monoclonal peak, Castleman disease, sclerotic bone disease, and elevated VEGF. The minor criteria consist of organomegaly, signs of extravascular volume overload (pleural effusion, ascites, and edema), endocrinopathy, polycythemia, papilledema, and skin changes. Organomegaly stands for lymphadenopathy, hepatomegaly, or splenomegaly [16, 21].

Polyneuropathy starts as a distal sensory loss, which later includes motor disabilities. Nerves 
have segmental demyelination, axonal degeneration, and immunostaining that show antimyelin antibodies [21].

Endocrinopathy has a wide range of manifestations, affecting either the pituitary or target organs. Secondary hypogonadism stands as the most common endocrine dysfunction in $70 \%$ of cases. Reports from the Mayo series, only available for males, features erectile dysfunction as the predominant symptom, followed by gynecomastia [16, 21]. The second most common endocrine manifestation is hypothyroidism in $58 \%$ of the patients, although it has a mild course. In third place, the Mayo series reported $48 \%$ with either impaired glucose tolerance or diabetes. The adrenal is rarely affected, but when it is, it usually manifests as primary adrenal insufficiency. Though prolactin is mildly elevated in most patients, only a small group exhibits irregular menses or galactorrhea. Parathyroids are rarely assessed, but some cases with secondary hyperparathyroidism have been described. Therefore, it is important to establish if calcium levels are altered due to these glands' dysfunction or secondary to bone turnover [16, $21,23]$. The pituitary compromise is infrequent, with few reports of adenomas resulting in panhypopituitarism and acromegaly [21, 24-25].

In $50-90 \%$ of patients, skin changes have been described. Hyperpigmentation is the most common sign while others include skin thickening, clubbing, white nails, acrocyanosis, and hirsutism [16, 21]. Paraneoplastic pemphigus has been linked to CD and recognized as a bad prognosis factor, although mostly associated with CD itself and not as part of the POEMS syndrome [26-28].

Sclerotic bone lesions are well described, mostly in association with POEMS syndrome, although isolated reports of MCD with a bone compromise without the POEMS spectrum are also available. In most cases, they are asymptomatic and are identified when an FDG-enhancing PET scan is performed to evaluate the extent of the disease. When biopsied, bone marrow has normal cellularity or a slight increase in plasma cells [29].

\section{Diagnosis}

Laboratory studies can show anemia, thrombocytosis, or thrombocytopenia. C-reactive protein, IL-6, and VEGF should be measured as well as liver function tests [22, 26]. One should note that, despite the systemic manifestations, some published cases have described normal levels of these cytokines and a normal CBC [4, 14, 22].

The endocrine workup must include central hormones and those produced in target organs. It should be performed not only initially, but also as a follow-up due to the emergence of new endocrinopathies in patients with POEMS syndrome [21].

There are no radiologic criteria; in general, MRI and CT may help identify hypervascularity by showing a higher enhancement in the hyaline vascular variant [30]. Calcifications can be found in this form but are rare in the plasma cell type, which usually shows lower enhancement [31].

Classic UCD appears as a solitary enlarged lymph node or clusters of nodes with intense homogeneous contrast enhancement. In fewer cases, imaging shows a dominant mass surrounded by normal lymphadenopathy (40\%) or matted lymphadenopathy alone without a dominant mass (10\%) [4, 31]. Nonetheless, depending on the location, UCD can mimic a variety of diseases, from thymoma and neural-crest-derived neoplasms in the mediastinum to pancreatic cancer and carcinoid in the abdomen [4].

MCD frequently exhibits generalized lymphadenopathy, comprising the abdomen, pelvis, mediastinum, neck, axilla, and inguinal regions. However, these nodal lesions resemble 
reactive or neoplastic diseases. Pulmonary centrilobular nodular parenchymal opacities suggest lymphocytic interstitial pneumonitis, common in $\operatorname{MCD}[4,11]$.

The immunocompromised groups of patients with HHV8-CD pose a higher degree of diagnostic difficulty, as lesions closely resemble opportunistic infections and lymphoma [4].

A positron emission tomography (PET) scan may be performed as follow-up and to stage the disease [4]. Usually, sclerotic bone lesions are a diagnostic finding. They appear as focal areas of more intense FDG uptake in the bone [29, 31].

The gold standard for diagnosis is an excisional biopsy from the lymph node; the fine needle aspiration is commonly undiagnostic. The hyaline vascular variant will show normal follicles with larger mantle zones forming concentric rings around atretic germinal centers, known as the "onion-skin phenomenon" [4]. Germinal centers exhibit increased overall vascularity, although there is a prominent penetrating vessel. The sinusoidal vessels are also enlarged, and perivascular hyalinization has been described $[2,4]$.

The plasma cell type histology is not unique and can be confounded with other inflammatory and infectious diseases. The lymph node architecture is preserved; germinal centers show mild hyperplasia with expanded mantle zones and paracortical plasmacytosis [2]. Abnormal clusters of monotypic plasma cells with restricted lambda IgG or IgA light chains have been reported as well [4].

HHV-8-associated CD shares plasma cell variant characteristics but is ruled out by clinical data and immunohistochemical staining [4].

\section{Treatment}

UCD has a good response to excisional surgery or localized radiation if that is not feasible. A complete surgical resection is the gold standard because of its excellent prognosis without remission after 20 years of follow-up [4, 32-35]. Intensity-modulated radiation therapy (IMRT) has been described as a novel radiotherapeutic approach for diseases located mainly in the thorax that represent difficult surgical access. It is better than 3D conformal techniques, as it reduces the dose gradient and toxicity to the surrounding normal tissues [36].

Due to the several systemic manifestations of MCD, surgery may give transient relief of symptoms but with a rebound effect, so it is not considered a good method [34-35, 37].

Among the drugs described, glucocorticoids (usually used as adjuvant therapy) improve symptoms and correct blood analyses abnormalities. However, the benefit is temporary. Antiangiogenic drugs, such as thalidomide, have also produced improvement [32, 38].

Currently, multidrug schema chemotherapy stands as the best option. It has induced remission in 50\% of cases with CHOP (cyclophosphamide, hydroxydaunorubicin (doxorubicin), oncovin (vincristine), and prednisone) or in 67\% with CVAD (cyclophosphamide, vincristine, Adriamycin, and dexamethasone) [32-33, 38].

Monoclonal antibodies, such as rituximab (anti-CD20) and tocilizumab (anti IL-6 receptor), have been described without enough evidence. However, one recently anti IL-6 drug, siltuximab, has shown efficacy and safety, reason by which FDA has already approved it as treatment [39-40].

Antiviral agents, anti HHV-8, such as ganciclovir, valganciclovir, cidofovir, or foscarnet, play a 
theoretical role. Nonetheless, a good response of valganciclovir and CHOP chemotherapy has been described in HIV-positive patients [32, 38]. This therapy must go in conjunction with highly active anti-retroviral therapy (HAART) after CD is diagnosed in this group [20].

Despite the therapy, the prognosis of MCD is poor, although it depends on the progression rate, infections, and comorbidities. These patients usually die from sepsis, multi-organ system failure (due to systemic inflammation), or malignancy (lymphoma is the most frequent) [38].

A radiological follow-up with CT is suggested six to 12 months after therapy for UCD. Subjects with MCD need a radiologic and serum follow-up with a complete blood count, liver function test, and C-reactive protein every six months or when there is a suspected clinical recurrence $[4,38]$.

\section{Conclusions}

Castleman disease is a rare condition of unknown etiology that affects lymphoid tissues in diverse locations. The clinical scenario depends mostly on the histologic type, which includes plasma cell, mixed cellular, plasmablastic, and hyaline vascular variant, the latter being the most common. The clinical presentation is explained through a number of cytokines (particularly IL-6 and VEGF) produced mainly by those variants with plasma cells. Among them, we find fatigue, pain in different locations of the body, cytopenias, and B- symptoms. The endocrinopathy is manifested as part of POEMS syndrome, where the pituitary gland is the most commonly affected organ. Excisional surgery stands as an excellent therapy for unicentric Castleman disease, while chemotherapeutic schemas with CHOP (cyclophosphamide, doxorubicin, vincristine, and prednisone) or with CVAD (plus dexamethasone) are better options for multicentric $\mathrm{CD}$ cases. The wide spectrum of clinical manifestations makes the diagnosis a challenge. This is one of the reasons that the incidence and prevalence of the disease are not only underestimated but has not even been well-established. Therefore, it is important that physicians consider this clinical entity so patients can receive adequate and early treatment.

\section{Additional Information}

\section{Disclosures}

Conflicts of interest: In compliance with the ICMJE uniform disclosure form, all authors declare the following: Payment/services info: All authors have declared that no financial support was received from any organization for the submitted work. Financial relationships: All authors have declared that they have no financial relationships at present or within the previous three years with any organizations that might have an interest in the submitted work. Other relationships: All authors have declared that there are no other relationships or activities that could appear to have influenced the submitted work.

\section{Acknowledgements}

We thank Diane Cooper, MSLS, NIH Library, for providing assistance in writing this manuscript.

\section{References}

1. Castleman B, Towne V: Case records of the Massachusetts General Hospital; weekly clinicopathological exercises. N Engl J Med. 1954, 251:396-400.

10.1056/NEJM195409022511008

2. Cronin DM, Warnke RA: Castleman disease: an update on classification and the spectrum of associated lesions. Adv Anat Pathol. 2009, 16:236-46. 10.1097/PAP.0b013e3181a9d4d3

3. Lin CY, Chang YL: Castleman's disease in the head and neck region: meta-analysis of reported 
cases in Taiwan and literature review. J Formos Med Assoc. 2010, 109:913-920.

10.1016/s0929-6646(10)60139-8

4. Bonekamp D, Hruban RH, Fishman EK: The great mimickers: Castleman disease. Semin Ultrasound CT MR. 2014, 35:263-71. 10.1053/j.sult.2013.12.005

5. Aguilar-Rodriguez R, Milea SL, Demirci I1, Herold S, Flasshove M, Klosterhalfen B, Kinkel H, Janßen H: Localized retroperitoneal Castleman's disease: a case report and review of the literature. J Med Case Rep. 2014, 8:93. 10.1186/1752-1947-8-93

6. Eward WC, DeWitt SB, Brigman BE, Kontogeorgakos V, Lagoo AS: Extranodal Castleman disease of the extremities: a case report and review of the literature. Skeletal Radiol. 2014, 43:1627-31. 10.1007/s00256-014-1945-z

7. Coca S, Salas I, Martínez R, Saez MA, Vaquero J: Meningeal Castleman's disease with multifocal involvement: a case report and review of literature. J Neurooncol. 2008, 88:37-41. 10.1007/s11060-008-9528-2

8. Hakozaki M, Tajino T, Yamada H, Kikuchi S, Hashimoto Y, Konno S: Intramuscular Castleman's disease of the deltoid: a case report and review of the literature. Skeletal Radiol. 2010, 39:715-19. 10.1007/s00256-010-0895-3

9. Iaconetta G, Friscia M, Dell'Aversana Orabona G, de Biasi S, Romano A, Piombino P, Graziano P, Abbate V, Salzano G, Maglitto F, Califano L: Castleman's disease mimicking a parotid gland tumor: report of a case and review of the literature. Eur Rev Med Pharmacol Sci. 2014, 18:1241-46.

10. Tunru-Dinh VW, Ghani A, Tom YD: Rare case of Castleman disease involving the pancreas . Am Surg. 2007, 73:1284-87.

11. Ogoshi T, Kido T, Yatera K, Oda K, Kawanami T, Ishimoto H, Sakamoto N, Sano A, Yoshii C, Shimajiri S, Mukae H: Assessment of pathologically diagnosed patients with Castleman's disease associated with diffuse parenchymal lung involvement using the diagnostic criteria for IgG4-related disease. Lung. 2013, 191:575-83. 10.1007/s00408-013-9497-x

12. Koppens JM, Pon JA, Allen J, Sloan BH: Castleman's disease of the lacrimal gland . Clin Experiment Ophthalmol. 2004, 32:108-10. 10.1046/j.1442-9071.2004.00771.x

13. Munshi N, Mehra M, van de Velde H, Desai A, Potluri R, Vermeulen J: Use of a claims database to characterize and estimate the incidence rate for Castleman disease. Leuk Lymphoma. 2015, 56:1252-60. 10.3109/10428194.2014.953145

14. Blanchard F, Duplomb L, Baud'huin M, Brounais B: The dual role of IL-6-type cytokines on bone remodeling and bone tumors. Cytokine Growth Factor Rev. 2009, 20:19-28.

10.1016/j.cytogfr.2008.11.004

15. Góth MI, Hubina E, Raptis S, Nagy GM, Tóth BE: Physiological and pathological angiogenesis in the endocrine system. Microsc Res Tech. 2003, 60:98-106. 10.1002/jemt.10248

16. Kenchaiah M, Sennik D, Ali HE, Beharry N, Wilson P, Anderson C, Schey S, Bano G: Endocrinopathy in polyneuropathy, organomegaly, endocrinopathy, monoclonal gammopathy and skin changes syndrome. Endocrinology Studies. 2013, 3:1-4. 10.4081/es.2013.e1

17. Arlet JB, Hermine O, Darnige L, Ostland V, Westerman M, Badoual C, Pouchot J, Capron L: Iron-deficiency anemia in Castleman disease: implication of the interleukin 6/hepcidin pathway. Pediatrics. 2010, 126:e1608-12. 10.1542/peds.2010-1123

18. Chandrakasan S, Bakeer N, Mo JQ, Cost C, Quinn CT: Iron-refractory microcytic anemia as the presenting feature of unicentric Castleman disease in children. J Pediatr. 2014, 164:928-30. 10.1016/j.jpeds.2013.11.026

19. Izuchukwu IS, Tourbaf K, Mahoney MC: An unusual presentation of Castleman's disease:a case report. BMC Infect Dis. 2003, 3:20. 10.1186/1471-2334-3-20

20. Choi JH, Jo YJ, Gong SJ, Hong BW, Lee HJ, Son BK, Jun DW, Kim SH, Park YS, Seok JW: Unicentric castleman disease is not clearly distinguished from multicentric type: a case report . Clin Lymphoma Myeloma. 2008, 8:256-59. 10.3816/CLM.2008.n.036

21. Gandhi GY, Basu R, Dispenzieri A, Basu A, Montori VM, Brennan MD: Endocrinopathy in POEMS syndrome: the Mayo Clinic experience. Mayo Clin Proc. 2007, 82:836-42.

$10.4065 / 82.7 .836$

22. Jackson A, Burton IE: A case of POEMS syndrome associated with essential thrombocythaemia and dermal mastocytosis. Postgrad Med J. 1990, 66:761-67.

23. Washington T, Vora A, Mihailescu D: A case of hypercalcemia associated with Castleman disease. Endocr Pract. 2010, 16:1007-11. 10.4158/ep10110.cr

24. Bruno C, Fleck JD, Cavaghan MK: Pituitary macroadenoma in a patient with POEMS syndrome 
in conjunction with Castleman disease: first report of a case and review of related literature. Endocr Pract. 2010, 16:97-101. 10.4158/ep09027.crr

25. Murphy PT, Ahmed N, Hassan HT: Chronic myeloid leukemia and acromegaly in POEMS syndrome. Leuk Res. 2002, 26:1135-37. 10.1016/S0145-2126(02)00076-0

26. Dong Y, Wang M, Nong L, Wang L, Cen X, Liu W, Zhu S, Sun Y, Liang Z, Li Y, Ou J, Qiu Z, Ren $\mathrm{H}$ : Clinical and laboratory characterization of 114 cases of Castleman disease patients from a single centre: paraneoplastic pemphigus is an unfavourable prognostic factor. $\mathrm{Br} \mathrm{J}$ Haematol. 2015, 169:834-42. 10.1111/bjh.13378

27. Dinesha, Padyana M, Nayak K, Nirupama M, Pai DS: Castleman's disease with paraneoplastic pemphigus. Indian J Dermatol. 2014, 59:421. 10.4103/0019-5154.135528

28. Marzano AV, Vezzoli P, Mariotti F, Boneschi V, Caputo R, Berti E: Paraneoplastic pemphigus associated with follicular dendritic cell sarcoma and Castleman disease. Br J Dermatol. 2005, 153:214-15. 10.1111/j.1365-2133.2005.06695.x

29. Ramos CD, Massumoto CM, Rosa MF, Mazo-Ruiz MF, Mitteldorf C, Etchebehere EC, Santos AO, Lima MC, Cerri GG, Camargo EE: Focal bone marrow involvement in multicentric Castleman disease demonstrated by FDG PET/CT. Clin Nucl Med. 2007, 32:295-96. 10.1097/01.rlu.0000257288.11595.32

30. Zheng X, Pan K, Cheng J, Dong L, Yang K, Wu E: Localized Castleman disease in retroperitoneum: newly discovered features by multi-detector helical CT. Abdom Imaging. 2008, 33:489-92. 10.1007/s00261-007-9273-6

31. Madan R, Chen JH, Trotman-Dickenson B, Jacobson F, Hunsaker A: The spectrum of Castleman's disease: mimics, radiologic pathologic correlation and role of imaging in patient management. Eur J Radiol. 2012, 81:123-31. 10.1016/j.ejrad.2010.06.018

32. Roca B: Castleman's disease: a review. AIDS Rev. 2009, 11:3-7.

33. Bowne WB, Lewis JJ, Filippa DA, Niesvizky R, Brooks AD, Burt ME, Brennan MF: The management of unicentric and multicentric Castleman's disease: a report of 16 cases and a review of the literature. Cancer. 1999, 85:706-17. 10.1002/(SICI)10970142(19990201)85:3<706::AID-CNCR21>3.0.CO;2-7

34. Talat N, Belgaumkar AP, Schulte KM: Surgery in Castleman's disease: a systematic review of 404 published cases. Ann Surg. 2012, 255:677-84. 10.1097/SLA.0b013e318249dcdc

35. Bejjani J, Lemieux B, Gariepy G, Younan R: Complete anemia reversal after surgical excision of mesenteric hyaline-vascular unicentric Castleman disease. Can J Surg. 2009, 52:E197-98.

36. Matthiesen C, Ramgopol R, Seavey J, Ahmad S, Herman T: Intensity modulated radiation therapy (IMRT) for the treatment of unicentric Castlemans disease: a case report and review of the use of radiotherapy in the literature. Radiol Oncol. 2012, 46:265-70. 10.2478/v10019012-0008-0

37. Maslovsky I, Uriev L, Lugassy G: The heterogeneity of Castleman disease: report of five cases and review of the literature. Am J Med Sci. 2000, 320:292-95. 10.1097/00000441-20001000000013

38. Casper C: The aetiology and management of Castleman disease at 50 years: translating pathophysiology to patient care. Br J Haematol. 2005, 129:3-17. 10.1111/j.13652141.2004.05311.x

39. Barquero N: Siltuximab: a new option for the management of Castleman's disease . Drugs Today (Barc). 2015, 51:21-28. 10.1358/dot.2015.51.1.2234002

40. Beck JT, Hsu SM, Wijdenes J, Bataille R, Klein B, Vesole D, Hayden K, Jagannath S, Barlogie B: Brief report: alleviation of systemic manifestations of Castleman's disease by monoclonal anti-interleukin-6 antibody. N Engl J Med. 1994, 330:602-5. 10.1056/nejm199403033300904 